Tropical Journal of Pharmaceutical Research May 2020; 19 (5): 965-970

ISSN: $1596-5996$ (print); 1596-9827 (electronic)

(C) Pharmacotherapy Group, Faculty of Pharmacy, University of Benin, Benin City, 300001 Nigeria.

\title{
Cordycepin reverses cisplatin resistance in human bladder cancer cells via the PTEN/PI3K/AKt pathway
}

\author{
Sheng Li, Li-bin Zhou*, Tie-lin Wu, Min Yin, Hui-min Long \\ Department of Urology Surgery, Li Huili Hospital of Ningbo Medical Center, Ningbo City, Zhejiang Province 315000, China \\ *For correspondence: Email: m40psz@163.com
}

Sent for review: 15 January 2020

Revised accepted: 25 April 2020

\begin{abstract}
Purpose: To study the influence of cordycepin (Cor) on cisplatin insensitivity in bladder carcinoma, and its underlying mechanism of action.

Methods: The effects of cisplatin and Cor treatments on the viability of T24-sensitive and T24/DDPinsensitive bladder carcinoma cells were investigated by using 3-(4,5-dimethyl-2-thiazolyl)-2,5-diphenyl2-H-tetrazolium bromide (MTT) method to assess selectivity index. Flow cytometry was employed to evaluate the apoptosis of T24/DDP-resistant bladder cancer cells treated with cisplatin and Cor. The concentrations of PTEN, p-AKt and Akt in T24/DDP-resistant bladder cancer cells treated with cisplatin and Cor were determined by western blot assay.

Results: Compared with T24-sensitive cells, the sensitivity of T24/DDP-resistant bladder cancer cells to cisplatin was significantly decreased, along with significant increase in half-inhibitory concentration $\left(I C_{50}\right)$ value, resulting in 10.56-fold increase in resistance $(p<0.05)$. The median effective concentration (EC50) value of Cor for DDP reversal was $1.03 \pm 0.15 \mu \mathrm{M}$, and it had a high selectivity index for normal cells (> 48.5). The results from flow cytometry showed that Cor significantly enhanced the apoptosisinducing capacity of DDP in T24/DDP-resistant cells $(p<0.05)$, while Western blot data indicate that $P T E N$ protein expression increased and phosphorylated Akt protein expression decreased in T24/DDPresistant cells after Cor treatment when compared with control group $(p<0.05)$.

Conclusion: Cordycepin significantly improves the sensitivity of T24/ DDP-resistant bladder cancer cells to cisplatin via a mechanism related to the activation of PTEN/AKt signaling pathway, thus indicating that it is a potential candidate reversing DDP-resistance in bladder cancer.
\end{abstract}

Keywords: Bladder cancer, Cordycepin, Cisplatin resistance, PTEN/Akt signaling pathway

This is an Open Access article that uses a fund-ing model which does not charge readers or their institutions for access and distributed under the terms of the Creative Commons Attribution License (http://creativecommons.org/licenses/by/4.0) and the Budapest Open Access Initiative (http://www.budapestopenaccessinitiative.org/read), which permit unrestricted use, distribution, and reproduction in any medium, provided the original work is properly credited.

Tropical Journal of Pharmaceutical Research is indexed by Science Citation Index (SciSearch), Scopus, International Pharmaceutical Abstract, Chemical Abstracts, Embase, Index Copernicus, EBSCO, African Index Medicus, JournalSeek, Journal Citation Reports/Science Edition, Directory of Open Access Journals (DOAJ), African Journal Online, Bioline International, Open-J-Gate and Pharmacy Abstracts

\section{INTRODUCTION}

The incidence of bladder cancer (BC), a common malignant tumor in the genito-urinary system is second only to prostate cancer in men, and it is a serious threat to human health [1]. The pathogenesis of malignant tumors is now much clearer due to advancements in medical technology. The treatment of BC is usually effective when it is diagnosed early enough [2]. In contrast, at late diagnosis, the aggressiveness and fatality of $\mathrm{BC}$ are already highly accentuated [3]. 
Chemotherapy has remained an irreplaceable treatment strategy for cancer. Cisplatin is a cytotoxic chemotherapy drug that destroys DNA in tumor cells, thereby channeling the cells into the apoptosis pathway [4]. Currently, cisplatin is widely used as a first-line chemotherapy drug in BC patients [5]. Moreover, cisplatin may be used as pre-surgery chemotherapy in combination with complete removal of urinary bladder, or as sole drug for treating $B C$ at the stage of metastasis [6]. Unfortunately, a significant population of patients experience pre-existing chemical resistance which limits the therapeutic effectiveness of cisplatin [7]. Although BC subjects respond initially, insensitivity to cisplatin eventually results, leading to poor prognosis [8]. Thus, it is necessary to develop more effective treatment strategies for advanced $B C$. This is important for predicting treatment outcomes and developing effective chemotherapeutic drugs. Adjuvant therapy is an effective method for improving the sensitivity of bladder cancer cells to cisplatin, and for reducing metastasis of tumor cells.

For thousands of years, natural products have been used to treat various fatal diseases. Among the many herbs, the genus Cordyceps has received special attention for its extensive biological properties. Cordycepin (Cor), a nucleoside analogue and a major bioactive component of Cordyceps sinensis, is known to mediate multiple pharmacological actions involving multiple signaling pathways of apoptosis, proliferation, metastasis, angiogenesis, and inflammation. However, no studies have been carried out to investigate whether cordycepin has inhibitory effect on cisplatin resistance in bladder cancer. Therefore, this study was aimed at investigating the effect of Cor on the resistance of bladder cancer cells to cisplatin, and the mechanism involved.

\section{EXPERIMENTAL}

\section{Cell culture}

Human bladder cancer cell line T24 from ATCC, USA, was cultured in RPMI-1640 supplemented with $10 \%$ FBS, and passaged every 2-3 days. The cells were incubated at $37{ }^{\circ} \mathrm{C}$ in an incubator containing $5 \% \mathrm{CO}_{2}$. Cisplatin-resistant T24 cells were prepared through gradient treatment with cisplatin. The T24 cells were first cultured in a medium containing $0.5 \mu \mathrm{M}$ cisplatin for 3 months, and then the cisplatin concentration was increased by $0.1 \mu \mathrm{M}$ every 3 weeks. Finally, T24 cells were steadily cultured in a medium containing $1.5 \mu \mathrm{M}$ cisplatin.

\section{Determination of cytotoxicity and resistance} reversal activity

Using published reports [9], T24 cells at logarithmic phase of growth phase were plated in 96 -well plates $\left(8 \times 10^{3}\right.$ cells $\left./ \mathrm{mL}\right)$, with $180 \mu \mathrm{L}$ per well. For cytotoxicity test, two groups of cells were used: blank control group and treatment group. Cells in the blank control group were treated with $20 \mu \mathrm{L}$ of $0.1 \%$ DMSO. The treatment group was treated with varying concentrations. After incubation for $48 \mathrm{~h}, 20 \mu \mathrm{L}$ MTT $(5 \mathrm{mg} / \mathrm{mL})$ was added to each well, and the culture medium was then removed by centrifugation for $4 \mathrm{~h}$. Then, dimethyl sulfoxide was used to dissolve the crystals formed, and absorbance was read in a microplate reader at $490 \mathrm{~nm}$. Using the readings, $\mathrm{IC}_{50}$ was calculated with GraphPad Prism 6.0 software.

For the resistance reversal activity test, the cells were incubated with varying concentrations of DDP and fixed concentration of Cor, and fixed concentrations of DDP and varying concentrations of Cor (each $10 \mu \mathrm{L}$ ). After incubation for $48 \mathrm{~h}$, cytotoxicity test was performed in order to calculate the degree of cell inhibition and $\mathrm{IC}_{50}$ value of combination of Adriamycin and test compound, and to calculate the reversal fold (RF). The inhibition of cell proliferation (P) and fold reversal (RF) of resistance (RF) were calculated as shown in Eqs 1 and 2 , respectively.

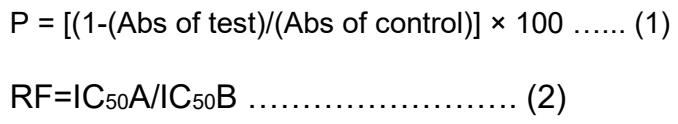

where $I C_{50 A}$ is $I C_{50}$ of DDP in T24-DDP cells, and $I C_{50 B}$ is $I_{50}$ of DDP in T24 cells.

\section{Studies on dose-effect relationship in reversal of resistance}

Resistance reversal was determined at different concentrations of SAS, based on results of the preliminary assay [10]. Serum-containing medium was used to dilute SAS to final concentrations of $20,10,5.0,2.5,1.25,0.625$, $0.31,0.156,0.078$ and $0.04 \mu \mathrm{M}$.

\section{Determination of selective index (SI)}

Selective index $(\mathrm{SI})$ refers to the relative affinity of a compound for normal cells or drug-resistant tumor cells. The $\mathrm{IC}_{50}$ value of the selected compound on gastric epithelial cell strain 1 (GES-1) of normal human gastric mucosa was determined using MTT method. The SI was calculated as shown in Equation 3: 
$\mathrm{SI}=I \mathrm{C}_{50} \mathrm{~A} / \mathrm{EC}_{50} \mathrm{~B}$

where $I C_{50 A}$ is the $I C_{50}$ value of the selected compound in GES-1 cells, and $E_{50 B}$ is the concentration of the selected compound when the $\mathrm{IC}_{50}$ value of DDP in K562/A02 was reduced by $50 \%$. The GES-1 cells were maintained in RPMI 1640 supplemented with $10 \%$ FBS (Gibco).

\section{Apoptosis test}

The T24-DDP cells were inoculated on 6-well plates at a density of $1 \times 10^{6}$ cells per well, and incubated overnight to adherence. Following treatment of the T24-DDP cells with $10 \mu \mathrm{M}$ cisplatin and quercetin for $48 \mathrm{~h}$, propidium iodide $(\mathrm{PI})$ and Annexin-V were added to the cells according to the instructions of the apoptosis detection kit manual, followed with incubation for $20 \mathrm{~min}$. Thereafter, apoptosis of T24-DDP cells was determined using flow cytometry.

\section{Western blot analysis}

The cells were cultured and allowed to grow to $80 \%$ confluence in 6-well plates. Thereafter, the 6 -well plate was placed on ice, and total protein was extracted from each well for 1 min using 150 $\mu \mathrm{L}$ of RIPA lysing reagent containing $1 \mathrm{mM}$ protease inhibitor and PMSF. The extract was centrifuged at $4{ }^{\circ} \mathrm{C}$ at $12000 \mathrm{rpm}$, and supernate protein content was quantified with bicinchoninic acid method. A fixed amount of the protein was subjected to SDS-polyacrylamide gel electrophoresis and transferred to polyvinylidene membrane.

Non-specific binding was blocked by incubating the membrane with $5 \%$ skim milk solution at room temperature for $1 \mathrm{~h}$. Then, it was subjected to incubation with $1^{\circ}$ antibodies for PTEN, Akt, pAKt and $\beta$-actin (at dilution ratios of 1:1000 $1: 2000)$ overnight at $4{ }^{\circ} \mathrm{C}$, with GAPDH (1:500 dilution) as loading control. Thereafter, the membrane was washed thrice with TBST, each wash for $10 \mathrm{~min}$. This was followed by incubation with secondary antibody overnight at room temperature. Gray image analysis was performed with ImageJ.

\section{Statistical analysis}

Data are expressed as mean \pm SD. One-way ANOVA was used for comparison of mean differences between groups, while $t$-test was used for two-group comparison. All statistical analyses were carried out with SPSS version 19.0 statistical software.

\section{RESULTS}

\section{In vitro cytotoxicity of Cor and drug resistance-fold of T24-DDP}

The $\mathrm{IC}_{50}$ values of DDP for T24 and T24-DDP cells were $2.81 \pm 0.37$ and $29.66 \pm 3.54 \mu \mathrm{M}$, respectively. Compared with the sensitive T24 cells, the drug-resistant T24/DDP cells showed significant resistance to DDP, with 10.56-fold drug resistance (Figure $1 \mathrm{~A}$ ). At all tested doses, the percentage growth of Cor-treated T24, T24DDP and GES- 1 cells exceeded $60 \%$ even at the highest concentration $(100 \mu \mathrm{M})$. However, the growth inhibition was less than $10 \%$ when the concentration was lower than $5 \mu \mathrm{M}$ (Figure 1 B). Thus, $5 \mu \mathrm{M}$ was taken as non-toxic dose which was used in subsequent resistancereversal experiments.

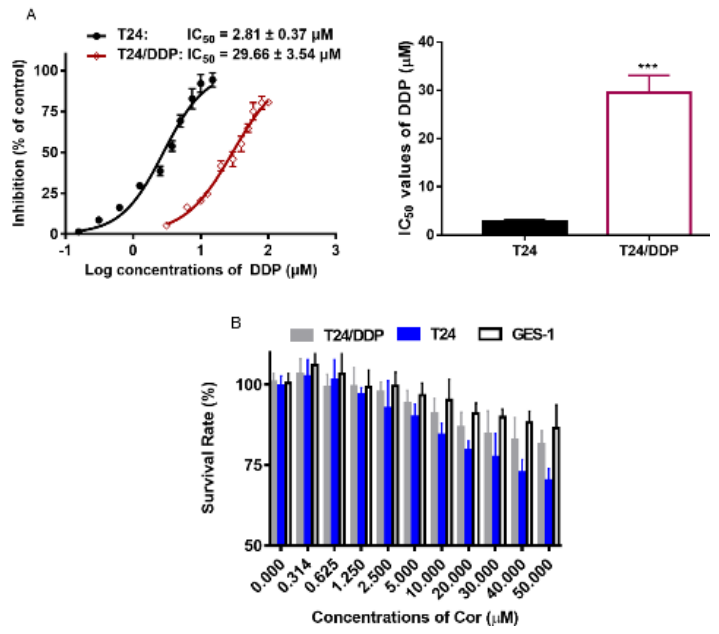

Figure 1: In vitro cytotoxicity of Cor and fold drug resistance of T24-DDP. (A) IC 50 values of DDP in the inhibition of T24 and T24-DDP cell lines, as determined by MTT assay. (B) cytotoxicity of Cor on T24, T24-DDP and GES-1 cell lines. Each datum point is presented as mean \pm SD for three independent tests. ${ }^{* *} P<0.001$, compared with T24 cells

\section{Resistance reversal effect and selection index of Cor}

At the same DDP concentration, when DDP was used in combination with Cor, the toxicity and the inhibitory effect of DDP on T24-DDP-resistant strains increased, while the $I_{50}$ of DDP decreased, and the fold resistance reversal effect of Cor increased concentration-dependently (Figure $2 \mathrm{~A}$ ). The $\mathrm{EC}_{50}$ value of Cor in the reversal of resistance of T24-DDP cells was calculated, and the concentration of Cor required for $50 \%$ reversal of resistance of T24-DDP cells was obtained. As shown in Figure $2 \mathrm{~B}$, Cor 
produced strong reversal of resistance, with $\mathrm{EC}_{50}$ value of $1.03 \pm 0.15 \mu \mathrm{M}$ in T24-DDP cells. The results showed that Cor was not cytotoxic to normal cells, and the survival of GES-1 cells was up to $80 \%$ even at the maximum concentration of $50 \mu \mathrm{M}$, Thus, the $\mathrm{IC}_{50}$ of Cor was greater than $50 \mu \mathrm{M}$, with $\mathrm{SI}>48.5$, indicating that Cor was very safe in normal cells, while reversing drug resistance.
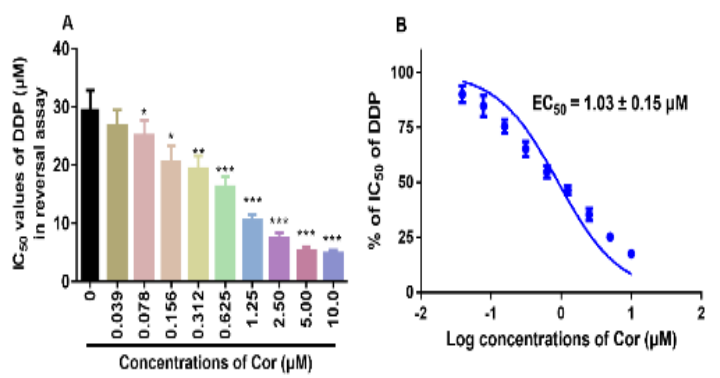

Figure 2: Reversal effect of Cor on DDP resistance in T24-DDP cells. (A) $I C_{50}$ values of DDP in T24/DDP cells exposed to DDP at variable levels of Cor; (B) $\mathrm{EC}_{50}$ value of Cor in lowering DDP-resistance in T24/DDP cells. The IC 50 of DDP was plotted against log concentration of Cor. $\mathrm{EC}_{50}$ is the concentration of modulator that reduces the $\mathrm{IC}_{50}$ of DDP by $50 \%$. Each datum point is presented as mean $\pm \mathrm{SD}(\mathrm{n}=3)$. ${ }^{*} P<$ $0.05,{ }^{* *} p<0.01,{ }^{* * *} p<0.001$, vs control

\section{Cordycepin enhanced the pro-apoptotic effect of DDP on T24-DDP}

As shown in Figure 3, combined treatment with Cor and DDP significantly promoted the apoptotic effect of DDP in T24/DDP cells $(p<$ 0.05).
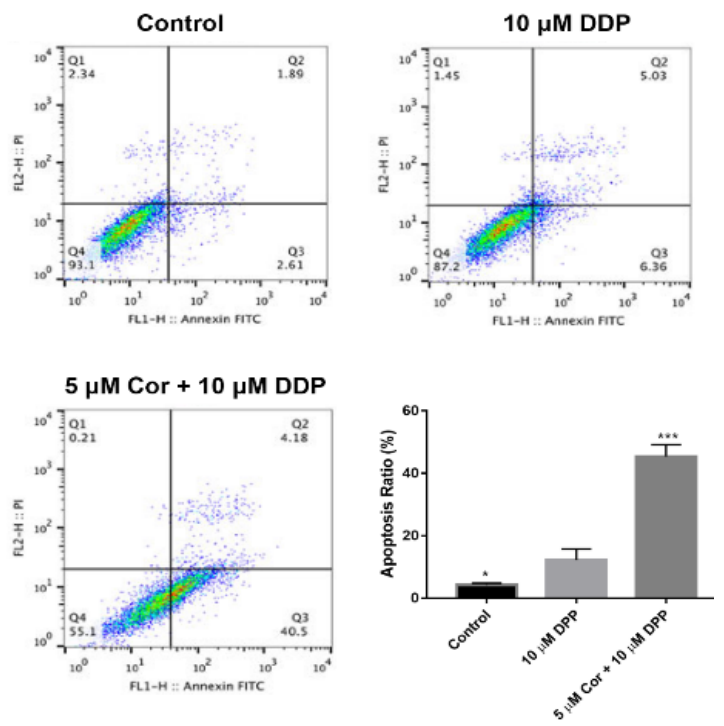

Figure 3: Influence of Cor on DDP-induced apoptosis in T24/DDP cells in vitro. Flow cytometry was used to determine apoptosis in T24/DDP cells. ${ }^{*} P<0.05,{ }^{* * *} p$ $<0.001$, compared with $10 \mu \mathrm{M}$ DDP group

\section{Influence of Cor on protein expressions in PTEN/Akt pathway}

Following treatment with the varying doses of Cor for $48 \mathrm{~h}$, the expression levels of PTEN, Akt and $\mathrm{p}$-AKt were determined using Western blotting. Relative to control, there was upregulated protein expression of PTEN, while the protein expression of $\mathrm{p}-\mathrm{AKt}$ decreased in the drug-treated group concentration-dependently ( $p$ $<0$. 05). There were no statistically significant differences in Akt expression among the groups $(p>0.05)$. These results are shown in Figure 4.
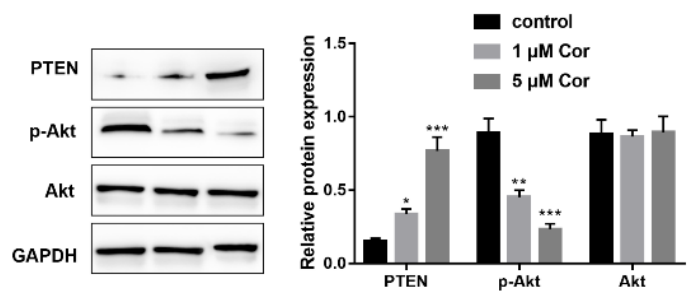

Figure 4: Effect of Cor on protein expressions. Values are mean $\pm \mathrm{SD}(\mathrm{n}=3) .{ }^{*} P<0.05,{ }^{* *} p<0.01,{ }^{* * *} p<$ 0.001 , vs control

\section{DISCUSSION}

Cordycepin (3'-deoxyadenosine) is a nucleic acid antibiotic which is the most widely studied bioactive component of Cordyceps sinensis with various pharmacological properties [11]. Cordycepin interferes with a variety of biological events, including synthesis of purines and nucleic acids, and mTOR signal cascade [12].

Studies have shown that Cor has an adjuvant effect on chemotherapy for malignant tumors. For example, Cor significantly enhances the toxicity of chemotherapy drugs on gallbladder carcinoma in humans. However, it is not clear if Cor has a chemotherapy-sensitizing effect on bladder cancer cells that have developed cisplatin resistance. The results of this study showed that bladder cancer cells with acquired cisplatin resistance had strong resistance to cisplatin in vitro, while cisplatin-resistant bladder cancer cells underwent significant apoptosis after concurrent use of Cor. These results indicate that Cor enhanced the sensitivity of cisplatin-resistant bladder cancer cells to cisplatin, while Cor and cisplatin exerted synergistic anti-tumor effect.

Studies have shown that PTEN, located at 10q23 and encoding phosphatase, is associated with tumor inhibition [13]. Moreover, PTEN is linked to pathogenesis of tumor. associated with cancer 
pathology, and its downregulation may lead to the development of resistance to chemotherapy drugs (DDP inclusive) in subjects with gastric, colon, lung breast cancers [14]. Stimulation of the PI3K/Akt pathway, a major route of cell survival, increases resistance to apoptosis [15].

A study by Chen et al showed that suppression of PI3K/AKT/mTOR pathway enhances susceptibility of A549/DDP resistant cells to cisplatin. The study demonstrated that wogonin inhibits the PI3K/Akt pathway, thereby increasing the sensitivity of colon cancer cells to DDP, and increasing apoptosis. These studies have shown that the PI3K/Akt route is linked to insensitivity of carcinoma cells to chemotherapy. The pathway is under the regulation of PTEN. Moreover, PTEN inhibits the PI3K function via phosphorylation of PIP3, resulting in downregulation of Akt route. However, studies have shown that impairment of PTEN function leads to PIP3 buildup and stimulation of P13K activation, thereby triggering the stimulation of its downstream Akt pathway.

\section{CONCLUSION}

The findings of this study indicate that treatment of T24-DDP cells with Cor leads to downregulation of PTEN and activation of PI3K/Akt signaling pathway, thereby inhibiting miR-106a-mediated cellular survival and DDP insensitivity. This is the first study to describe the relationship amongst $\mathrm{PTEN}$, miR-106a and DDP insensitivity in gastric carcinoma, which provides a potential candidate reversing DDP-resistance in bladder cancer.

\section{DECLARATIONS}

\section{Acknowledgement}

This paper was supported by Medical and Health Science and Technology Project of Zhejiang Province (grant numbers: 2019KY603 and 2020KY858).

\section{Conflict of interest}

No conflict of interest associated with this work.

\section{Contribution of authors}

We declare that this work was done by the author(s) named in this article and all liabilities pertaining to claims relating to the content of this article will be borne by the authors. All authors read and approved the manuscript for publication. Li-bin Zhou conceived and designed the study, Sheng Li, Li-bin Zhou, Tie-lin Wu, Min Yin, Hui-min Long collected and analyzed the data, while Sheng Li wrote the manuscript.

\section{Open Access}

This is an Open Access article that uses a funding model which does not charge readers or their institutions for access and distributed under the terms of the Creative Commons Attribution License (http://creativecommons.org/licenses/by/ 4.0) and the Budapest Open Access Initiative (http://www.budapestopenaccessinitiative.org/rea d), which permit unrestricted use, distribution, and reproduction in any medium, provided the original work is properly credited.

\section{REFERENCES}

1. Siegel RL, Miller KD, Jemal A. Cancer statistics, 2019. CA Cancer J Clin 2019; 69(1): 7-34.

2. Rentsch CA, Müller DC, Ruiz C, Bubendorf $L$. Comprehensive molecular characterization of urothelial bladder carcinoma: a step closer to clinical translation? Eur Urol 2017; 72: 960-961.

3. Kamat AM, Hahn NM, Efstathiou JA, Lerner SP, Malmström PU, Choi W, Guo CC, Lotan Y, Kassouf W. Bladder cancer. Lancet 2016; 388(10061): 2796-2810.

4. Dilruba S, Kalayda GV. Platinum-based drugs: past, present and future. Cancer Chem Pharmacol 2016; 77(6): 1103-1124.

5. Chang SS, Bochner BH, Chou R, Dreicer R, Kamat AM, Lerner SP, Lotan Y, Meeks JJ, Michalski JM, Morgan TM. Treatment of non-metastatic muscle-invasive bladder cancer: AUA/ASCO/ASTRO/SUO guideline. J Urol 2017; 198(3): 552-559.

6. McConkey DJ, Choi W, Ochoa A, Siefker-Radtke A, Czerniak B, Dinney CP. Therapeutic opportunities in the intrinsic subtypes of muscle-invasive bladder cancer. Hematol 2015; 29(2): 377-394.

7. Choi W, Porten S, Kim S, Willis D, Plimack ER, HoffmanCensits J, Roth B, Cheng T, Tran M, Lee IL. Identification of distinct basal and luminal subtypes of muscle-invasive bladder cancer with different sensitivities to frontline chemotherapy. Cancer Cell 2014; 25(2): 152-165.

8. Naito S, Yokomizo A, Koga H. Mechanisms of drug resistance in chemotherapy for urogenital carcinoma. Int J Urol 1999; 6(9): 427-439.

9. Levy ES, Samy KE, Lamson NG, Whitehead KA, Kroetz $D L$, Desai TA. Reversible inhibition of efflux transporters by hydrogel microdevices. Eur J Pharm Biopharm 2019; 145: 76-84.

10. Chan KF, Wong IL, Kan JW, Yan CS, Chow LM, Chan TH. Amine Linked Flavonoid Dimers as Modulators for P-Glycoprotein-Based Multidrug Resistance: StructureActivity Relationship and Mechanism of Modulation. J Med Chem 2012; 55(5): 1999-2014.

Trop J Pharm Res, May 2020; 19(5): 969 
11. Vongsangnak $W$, Raethong N, Mujchariyakul W, Nguyen NN, Leong HW, Laoteng K. Genome-scale metabolic network of Cordyceps militaris useful for comparative analysis of entomopathogenic fungi. Gene 2017; 626: 132-139.

12. Han NR, Kim HY, Kang S, Kim MH, Yoon KW, Moon PD, Kim HM, Jeong HJ. Chrysophanol, an anthraquinone from AST2017-01, possesses the anti-proliferative effect through increasing p53 protein levels in human mast cells. Inflamm Res 2019; 68(7): 569-579.

13. Ohshima $K$, Fujiya $K$, Nagashima $T$, Ohnami $S$, Hatakeyama K, Urakami K, Naruoka A, Watanabe Y, Moromizato $S$, Shimoda $Y$, et al. Driver gene alterations and activated signaling pathways toward malignant progression of gastrointestinal stromal tumors. Cancer Sci 2019; 110(12): 3821-3833.

14. Chen J, Zhou C, Li J, Xiang X, Zhang L, Deng J, Xiong J. miR-21-5p confers doxorubicin resistance in gastric cancer cells by targeting PTEN and TIMP3. Int $\mathrm{J} \mathrm{Mol}$ Med 2018; 41(4): 1855-1866.

15. Mayer IA, Arteaga CL. The PI3K/AKT pathway as a target for cancer treatment. Annu Rev Med 2016; 67: 11-28.

16. Chen LM, Song TJ, Xiao JH, Huang ZH, Li Y, Lin TY. Tripchlorolide induces autophagy in lung cancer cells by inhibiting the PI3K/AKT/mTOR pathway and improves cisplatin sensitivity in A549/DDP cells. Oncotarget 2017; 8(38): 63911-63922. 